\title{
APRESENTAÇÃO
}

\section{A HABITAÇÃO NA APROXIMAÇÃO ENTRE UNIVERSIDADE, PODER PÚBLICO E SOCIEDADE}

O seminário Habitação como patrimônio cultural promovido pelo Centro de Preservação Cultural da USP (CPC-USP) ${ }^{1}$, realizado em maio de 2016 no auditório da Biblioteca Brasiliana Mindlin, colocou em diálogo as diferentes interpretações e experiências com o patrimônio residencial, estreitando as relações entre universidade, poder público e sociedade que abriu novas possibilidades de leitura e de compreensão da complexidade desse patrimônio. A habitação abriga a vivência humana composta de situações e realidades das mais diversas, ao mesmo tempo é o reduto da intimidade. É a tipologia predominante das cidades, uma manifestação estética que informa sobre o desenvolvimento das artes e das técnicas construtivas ao longo dos tempos. Um espaço que encerra os modos de vida, sobre os quais é possível perscrutar a dinâmica familiar, e as relações políticas, econômicas e sociais dos vários períodos. O tema da moradia diz respeito à própria existência, como escreveu Bachelard, A casa, mais ainda que a paisagem, é "um estado de alma”. Mesmo

\footnotetext{
1. O seminário contou com o apoio da FAPESP e CAPES. Comissão Científica: Mônica Junqueira de Camargo e Fernanda Fernandes (diretora e vice-diretora do Centro de Preservação Cultural da USP), Hugo Segawa (FAU-USP); Eneida de Almeida da (USJ) e Sabrina Fontenelle (CPC-USP).
} 
reproduzida no seu aspecto exterior fala de uma intimidade ${ }^{2}$, suscitando a investigação de muitas áreas do conhecimento: psicologia, antropologia, sociologia, história, geografia, meio ambiente, arquitetura, urbanismo, artes, engenharia e mais recentemente vem subsidiando pesquisas sobre domesticidade e gênero. Enfim, um bem cultural que ilustra a aliável relação entre a natureza material e imaterial do patrimônio, que alimenta estudos não só de várias áreas, como incita a transdisciplinariedade.

Como bem arquitetônico está presente em quase todos os manuais da história da arquitetura, é também um dos temas mais recorrentes de monografias e estudos acadêmicos. Considerando o cenário brasileiro, do binômio casa grande-senzala aos complexos de habitação de interesse social, há um vasto e rico patrimônio a partir do qual se pode especular a conformação da nossa sociedade. No entanto, é uma das tipologias que apresenta maior dificuldade de preservação, em todas as suas etapas: no reconhecimento, na documentação, na conservação e na apropriação, envolvendo quase sempre muita polêmica em quaisquer delas. A privacidade própria do espaço doméstico é conflitante com seu reconhecimento como bem cultural, de caráter público. A moradia é, com raras exceções, propriedade privada e, algumas vezes, o maior ou único patrimônio familiar, sobre a qual as normativas acabam por incidir no seu valor.

Apesar das dificuldades, são centenas de imóveis tombados no âmbito federal, estadual ou municipal, sendo alguns deles reconhecidos em duas ou mesmo nas três instâncias. O critério de valor histórico ou de excepcionalidade para o reconhecimento do patrimônio, vigente até meados do século xx nos órgãos públicos, não evitou o desaparecimento de importantes bens culturais. $\mathrm{O}$ alargamento do conceito a partir de então despertou a atenção para um conjunto muito mais amplo de habitações. Passaram a interessar também as moradias operárias ou a produção anônima, aquela que, de fato, caracteriza o ambiente urbano, cuja documentação gráfica, na maioria dos casos, inexiste, tornando o levantamento do imóvel mais difícil e moroso.

Considerando a vasta quantidade de casas de interesse histórico, definir critérios de seleção e medidas de sua preservação tem sido um dos desafios dos órgãos de patrimônio. $\mathrm{O}$ tombamento como o único instrumento de proteção 
não atende à demanda e às especificidades de cada situação. Os inventários com ampla documentação podem ser igualmente uma forma de preservação, porém, para tanto, o fortalecimento do corpo técnico das instituições patrimoniais é absolutamente necessário que, infelizmente, não é o que temos acompanhado.

A apropriação e o restauro da residência são intervenções técnicas que devem seguir os princípios estabelecidos nas cartas patrimoniais. Apesar de atender à condição básica da existência humana, como evidenciou Heiddeger na sua sempre evocada conferência de 1956 Construir, Pensar e Habitar, nas residências tombadas raramente é mantido o uso doméstico, boa parte, talvez a maioria é transformada em museu ou centro cultural. No Brasil, segundo os critérios do Comitê Internacional - DEMHIST há mais de 300 museus-casas históricas, entre sobrados, palácios, palacetes, casas rurais e moradias simples. A partir do conceito que agrega todo esse acervo, "o museu-casa conecta o espaço físico, o acervo de bens originais da edificação ou representativo do período e as relações de vida humana nesses ambientes"3, foram propostas nove categorias de classificação: casa de personalidade, de colecionador, de beleza, de eventos históricos, de sociedade local, ancestral, de poder, clerical e vernacular ${ }^{4}$.

Entre os bens tombados pelo Conpresp na cidade de São Paulo há 56 de uso residencial. A dinâmica de transformação metropolitana provoca forte pressão para a demolição ou transformação das residências unifamiliares, tanto que das 35 tombadas apenas quatro ainda se mantém como moradias, das três vilas operárias, a Vila Inglesa está ocupada apenas por serviços enquanto a Vila Economizadora e a Vila Maria Zélia compartilham serviço e habitação. Já os sete edifícios estritamente de apartamentos continuam como moradia e com alta procura para compra ou aluguel. Como as fachadas dos edifícios são coletivas, não permitem intervenções individuais, e as mudanças internas dos apartamentos são permitidas, o tombamento nesses casos acaba por agregar valor ao imóvel.

O programa residencial também é pouco recorrente para a apropriação de outras tipologias a serem restauradas, sugerindo que a moradia deva estar sempre associada ao novo, condição que se fortalece em um ambiente que se

3. CARVAlHO, Ana Cristina (org.). Museus-Casas Históricas no Brasil. São Paulo: Curadoria do Acervo Artístico Cultural dos Palácio de Governo do Estado de São Paulo, 2013. p.8 4. Idem. p.12 
caracteriza pela constante renovação, como o caso da cidade de São Paulo. Por um lado, a pressão de adensamento seja de áreas com baixa densidade demográfica, como os bairros ocupados por casas térreas ou sobrados, seja de setores fabris desativados pela mudança do sistema produtivo verificada nas últimas décadas, vem promovendo a rápida transformação de extensas áreas da cidade com a demolição de significativo patrimônio residencial.

Por outro lado, a mudança do eixo financeiro e de serviços para outras regiões da cidade vem provocando o esvaziamento dos edifícios da área central, que sem uma forte política de reversão desse potencial construtivo para outros usos, inclusive residencial, tem comprometido a qualidade do ambiente da área central inibindo o interesse de novos moradores, bem como a permanência daqueles que há muito lá vivem. Os edifícios de escritórios abandonados, muitos deles tombados, vêm suscitando a ocupação informal. Foram promovidas algumas iniciativas para a revitalização de edifícios comerciais ou de hotéis para o uso habitacional, mas infelizmente não teve continuidade.

A consolidação da ocupação informal das áreas periféricas, muitas delas em áreas de proteção ambiental, é incompatível com a nova legislação, levando a um impasse para a regularização e reurbanização dessas áreas carentes de infraestrutura. A reorganização desses trechos da cidade exige criterioso levantamento do ambiente estabelecido, fruto do modo de viver dessas pessoas, um dado cultural fundamental que não pode ser desprezado.

Perscrutar as formas de morar envolve toda a cidade e a proposta desse seminário foi estabelecer, a partir da apresentação de múltiplas experiências, um diálogo entre os vários agentes envolvidos: de pesquisas consagradas e sua repercussão no conhecimento e preservação dos bens culturais, às experiências em intervenção, gestão e convivência com o patrimônio residencial construído, tendo conseguido reunir 30 especialistas durante dois dias. Para melhor explorar a complexidade do tema e promover o debate, os trabalhos foram divididos em seis mesas temáticas: habitação como objeto de pesquisa; apropriação do patrimônio residencial; morar no patrimônio; preservação e o desafio coletivo; habitar na metrópole; a complexidade e os desafios da habitação como patrimônio, além de duas conferências internacionais - Preservação e Reutilização das Casas do Movimento Moderno por Louise Noelle, da Universidade Autónoma del México; e Mais que a casa: dois conjuntos modernos de moradias norte-americanas por Marc Treib, da Universidade da California. 
Os trabalhos selecionados para a mesa Habitação como objeto de pesquisa são Reconhecidas referências que abriram caminhos para novas leituras sobre o significado dessa tipologia no seu contexto histórico, contribuindo para a identificação e preservação do patrimônio residencial. Residências Paulistas, de 1977, de Marlene Milan Acayaba é um trabalho pioneiro no âmbito da academia a ter como objeto de pesquisa o patrimônio residencial moderno, antes mesmo do DOCOMOMO - um movimento internacional para a documentação e conservação do patrimônio moderno, criado em 1988. Com levantamento e metodologia inéditos, tornou-se uma referência para o estudo das residências modernas. Com as apresentações de Carla Coelho e Clara d'Alambert estendeu-se o tema aos edifícios residenciais à produção anônima do período entre guerras na cidade de São Paulo.

Sob a perspectiva da Apropriação do patrimônio residencial, a contraposição exposta pelos casos apresentados ilustra a diversidade de usos e interpretações que as casas tombadas têm permitido. A constituição de um padrão para as sedes de fazendas paulistas do período colonial identificada por Lia Mayumi; a problemática das casas-museus ilustrada pela casa de Rui Barbosa apresentada por Cláudia Carvalho; a apresentação do projeto vencedor do concurso público de 2015 para a adaptação da Residência Franco de Melo ao Museu da Diversidade Sexual, por Pablo Hereñu, e a intervenção de Angelo Bucci na Casa Baeta para adequá-la às necessidades domésticas contemporâneas suscitaram muitas especulações sobre a dimensão do patrimônio residencial.

O desafio de morar no patrimônio enfrentado por moradores em situações distintas fez da mesa Morar no patrimônio uma contribuição inusitada. Os depoimentos comentados por Eneida de Almeida que integram este dossiê compartilham os impactos, as dificuldades e a convivência com o patrimônio. A experiência da preservação de uma residência é muitas vezes entendida como uma punição que recai sobre o morador, que nos edifícios é amenizada pelo seu próprio caráter coletivo, como ficou evidenciado pelos trabalhos sobre o Conjunto Pedregulho de Afonso Eduardo Reidy, sobre o processo participativo para a preservação da Vila Maria Zélia; sobre a domesticidade dos apartamentos duplex ou ainda na polêmica obra de Artacho Jurado, discutidos sob a ótica da Preservação e o desafio coletivo. 
A diversidade e a complexidade inerentes à dimensão metropolitana constituem per si desafios à preservação cultural, que reverberam em diferentes situações urbanas, tais como: o enfretamento das ocupações informais em consonância à dinâmica social existente; a relação do novo com as pré-existências; a exploração do potencial habitacional do patrimônio edificado; a garantia do caráter de certas áreas residenciais; e a pressão do mercado imobiliário frente à transformação do sistema produtivo e obsolescência de suas instalações, que as apresentações do projeto Favela bairro por Jorge Jauregui; da revitalização de um edifício de escritórios para habitação de interesse social; das implicações do tombamento do traçado urbano do Jardim América e da pressão do mercado imobiliário sobre as áreas industriais desativadas ilustraram o embate travado entre o próprio poder público.

A exposição final dos representantes dos órgãos de preservação das três instâncias governamentais: municipal, estadual e federal sobre as suas respectivas políticas públicas para a preservação do patrimônio residencial refletiu mais a dificuldade no enfrentamento do problema do que possíveis alternativas de condução dos embates levantados. Victor Hugo Mori, representando o Iphan; José Eduardo Assis Lefèvre, respondendo pelo Condephaat e Nádia Somekh, com a presidência do Conpresp, trouxeram diferentes leituras sobre a preservação da moradia.

A troca de ideias sobre as diversas vivências que os vários segmentos sociais: poder público, legisladores, pesquisadores, acadêmicos, proprietários e mercado imobiliário apresentaram nesse seminário, constitui uma contribuição inédita que pode ser constatada no próprio formato dos diferentes artigos que deram origem a este dossiê. Comunicações acadêmicas, relatos, depoimentos que suscitaram grande interesse e estimularam um debate, reunindo iniciativas fragmentadas que podem convergir a um esforço comum, despertar novas pesquisas e a curiosidade de um público ampliado, e poder repercutir no desenvolvimento de trabalhos futuros. Promover a ampla difusão do conhecimento científico por meio da relação entre universidade e sociedade é uma das atribuições do CPC.

Mônica Junqueira de Camargo 